\title{
Assessing the Success of the Lunawa Restoration Project: Six Years Post Restoration
}

\author{
Fernando T., Wijesinghe M.R. ${ }^{*}$ and Mahees M.T.M.
}

\author{
Department of Zoology, Faculty of Science, University of Colombo, Colombo 03, Sri Lanka \\ *mayuri@zoology.cmb.ac.lk
}

\begin{abstract}
The Lunawa lagoon, receives large amounts of untreated industrial effluents and domestic waste water due to its industrialized and urbanized setting. As a result, the once pristine lagoon progressively deteriorated, ultimately becoming a health hazard to those living in close proximity. Many restoration programmes, of differing magnitudes, were undertaken from time to time; the most recent being that by the Coast Conservation Department in 2007. The objective of the present study is to assess the status of the lagoon in terms of water quality and avifaunal diversity six years after restoration.
\end{abstract}

This study was conducted from April to July 2013 during which selected water quality parameters in surface water were monitored at ten stations across the lagoon each month. An avifaunal survey was also conducted along six transects twice a month over the four months. On each day birds were observed between 0700 and $1000 \mathrm{hrs}$ at equally spaced points along these transects. The levels of many of the parameters were significantly different between sites. The ranges recorded were $\mathrm{pH}$ : 7.0 - 10.4, salinity: 0.7-8.1 ppm, conductivity: 4.7 $4058.0 \mu \mathrm{S}$, turbidity: 4.29-69.32 NTU, dissolved oxygen (DO): $2.3-14.9 \mathrm{mgl}^{-1}$, Biological Oxygen Demand (BOD) 5 day: 7.9 - $23.2 \mathrm{mg} \mathrm{l}^{-1}$, nitrate: $1.4-8.4 \mathrm{mg} \mathrm{l}^{-1}$, phosphate: 0.0 - $4.9 \mathrm{mg}$ $\mathrm{l}^{-1}$ and chloride: $461.5-2875.5 \mathrm{mg} \mathrm{l}^{-1}$. The mean values for conductivity and BOD were significantly lower $(\mathrm{p}<0.05)$ and DO significantly higher $(\mathrm{p}<0.05)$, than the values reported for the lagoon prior to restoration. Although recorded previously in lagoon water, the heavy metals, $\mathrm{Cr}, \mathrm{Pb}$, and $\mathrm{Cu}$ were not detected during the present study. $\mathrm{Zn}\left(0.31 \mathrm{mg} \mathrm{l}^{-1}\right)$ was only detected from the eastern drainage basin. Thus the present status suggests gradual transformation of the water quality in the lagoon since restoration. The avifaunal survey did not show similarly positive trends. A total of 31 resident species of terrestrial and aquatic birds were recorded during the present survey. The mean abundance of the birds on each day was 57. Both these values were lower than that reported in previous surveys. It was noteworthy though is the re-colonization of some species such as the spot-billed pelican, pied king fisher, white ibis, and the grey heron. It is likely that the major reasons for the low abundance of birds at present is the absence of riparian vegetation and trees along the banks of the lagoon, which were cleared (but replanted since) during the process of restoration.

The improvement of the water quality of the lagoon over the six years post restoration indicates that these efforts have been successful. It appears that it is too premature to arrive at conclusions with regard to the bird community. But, with time, the re-establishment of the bank vegetation would very likely facilitate recolonization of a more diverse biotic community.

Keywords: Bird diversity, Lunawa lagoon, Ecological restoration, Water quality 